\title{
Including Learning Analytics in the Loop of Self-Paced Online Course Learning Design
}

\author{
Hongxin Yan $^{1} \cdot$ Fuhua Lin $^{2} \cdot$ Kinshuk $^{3}$ \\ Accepted: 1 October 2020 / Published online: 9 December 2020 \\ (C) The Author(s) 2020
}

\begin{abstract}
Online education is growing because of its benefits and advantages that students enjoy. Educational technologies (e.g., learning analytics, student modelling, and intelligent tutoring systems) bring great potential to online education. Many online courses, particularly in self-paced online learning (SPOL), face some inherent barriers such as learning awareness and academic intervention. These barriers can affect the academic performance of online learners. Recently, learning analytics has been shown to have great potential in removing these barriers. However, it is challenging to achieve the full potential of learning analytics with the traditional online course learning design model. Thus, focusing on SPOL, this study proposes that learning analytics should be included in the course learning design loop to ensure data collection and pedagogical connection. We propose a novel learning design-analytics model in which course learning design and learning analytics can support each other to increase learning success. Based on the proposed model, a set of online course design strategies are recommended for online educators who wish to use learning analytics to mitigate the learning barriers in SPOL. These strategies and technologies are inspired by Jim Greer's work on student modelling. By following these recommended design strategies, a computer science course is used as an example to show our initial practices of including learning analytics in the course learning design loop. Finally, future work on how to develop and evaluate learning analytics enabled learning systems is outlined.
\end{abstract}

Keywords Self-paced online learning · Learning analytics · Student modelling · AIED · Learning data $\cdot$ Course learning design $\cdot$ Intervention

\section{Hongxin Yan \\ hongya@student.uef.fi \\ Fuhua Lin \\ oscarl@athabascau.ca}

Kinshuk

kinshuk@unt.edu

Extended author information available on the last page of the article 


\section{Introduction}

Online education is growing and creating enormous learning opportunities for learners. The vast amounts of learning-related data in online environments are significantly empowering intelligent computing technologies to enhance learning. One such technology is learning analytics (LA). Siemens and Long (2011) defines Learning Analytics as "the measurement, collection, analysis and reporting of data about learners and their contexts, for purposes of understanding and optimizing learning and the environments in which it occurs."

For online education, LA brings massive potential in various dimensions - monitoring, prediction, tutoring, feedback, adaptation, personalization, recommendation, and reflection (Wong and Li 2020; Chatti et al. 2012). Since the early stages, LA has been used to predict learning success and to identify at-risk students at the course or program level. More recently, LA has started to include more sophisticated analysis of learning processes, aiming for a more in-depth understanding of students' learning experiences at the topic or concept level (Mangaroska and Giannakos 2018). Such deeper level analysis can provide timely, actionable, and personalized insights to students and instructors, scale up personalized and adaptive learning, and examine the strengths and weaknesses of online courses (Gašević et al. 2015; Jovanović et al. 2017; Mangaroska and Giannakos 2018).

One popular online educational stream is self-paced online learning (SPOL), where students mainly employ the asynchronous and individualized study approach. In SPOL, students can learn not only anywhere and anytime, but also at any pace and via any pathway for their individuals' learning needs. Students may submit assignments whenever completed (e.g., even at the very end of a course duration). Thus, SPOL offers considerable flexibility for learners, especially adult learners who usually have work and family commitments.

This flexibility of SPOL, however, also imposes some barriers to learning. Because direct student-instructor interaction is not available and students learn in an individualized mode, the social interaction of student-instructor and student-student is often missing. Many students feel isolated and lack information on how they are doing compared with their peers.

As most online courses are currently designed using a one-size-fits-all model, a course could be too hard or too easy for different student groups. Also, many courses are created in the way of learning materials plus summative assessment (assignments and examinations), and students can choose to submit all the assignments towards the very end of the course duration. Hence, students may receive very little formative feedback during the course, despite that feedback is among the most critical influences on student achievement (Carless and Boud 2018). Without social interaction and formative feedback, students usually lack self-awareness of learning (e.g., how they are doing, where the learning gaps are, what to do to improve learning). The lack of learning awareness creates challenges for students in terms of seeking help, motivating themselves, and regulating learning (Zimmerman 2000).

The nature of SPOL also causes some challenges to course instructors. The instructor often finds it difficult to follow students' learning progress and monitor their knowledge mastering. As a result, the instructor may not be able to provide in-time and formative feedback to students, identify struggling students or detect the ineffective learning materials in a course. 
According to Lee and Choi (2011), these inherent learning barriers are among the factors that cause academic failures in SPOL. In general, many online courses experience high academic failure rates, usually higher than traditional face-to-face education (Park and Choi 2009; Stone 2017). So, it is critical for educators and researchers to find solutions that can mitigate these learning barriers. Given LA's potential in various dimensions (Wong and Li 2020; Chatti et al. 2012), this study has been investigating the possibility of using LA to address the learning barrier issues in SPOL and, therefore, to improve students' learning success.

The rest of this paper is organized as follows: second section discusses what LA applications can help to overcome these learning barriers; third section explains the limitation of current learning design practices for LA implementation; fourth section describes a new model and a set of course design strategies that aim to include the LA in the course design loop; fifth section uses a case study to illustrate how to follow the design strategies to revise a SPOL course and implement LA applications in it.

\section{LA Applications Used for SPOL}

To remove the inherent learning barriers identified for SPOL, three critical LA applications are recommended by the study: a) increasing learning awareness, b) identifying struggling students, and c) providing academic intervention. Other advanced applications, such as personalized learning, can be further investigated in the future based on the first three applications.

\section{Increasing Learning Awareness}

In SPOL, students' self-awareness of knowledge state and learning gaps can help them to reflect on learning and seek for help. To instructors, the awareness of students' learning status can assist them in initiating meaningful social connections with students and offering academic interventions to struggling students.

In the learning analytics field, tools like dashboard or visualization of learning data and concepts like open learner model or student modelling have been explored for increasing the learning awareness (Bodily et al. 2018). For example, the LA dashboard has been developed for social comparison, goal achievement, and learning progress reference (Jivet et al. 2017). Social comparison with peer students can motivate students to work harder, increase their engagement, and induce "a feeling of being connected with and supported by their peers" (Venant et al. 2016).

\section{Identifying Struggling Students}

Just making students and instructors aware of students' knowledge and skill state is not enough (Jivet et al. 2017). Identifying struggling students for timely support is also essential. In addition to predicting who could drop out or fail a course at the end, using LA at a more fine-grained level to identify who gets stuck at a topic or concept level is even more important. An LA predictive model, like regression (Baker and Inventado 2014), can be used for this purpose. 


\section{Providing Academic Intervention}

To help instructors provide those struggling students with effective intervention, reasons why a student is struggling or stuck with a topic or a concept must be examined. For example, being stuck could be caused by low levels of prior-knowledge, insufficient learning efforts, or ineffective course materials. An LA diagnostic model, like classification (Baker and Inventado 2014), can be adopted for such an LA application.

\section{The Limitation of Current Learning Design for LA Implementation}

To implement LA applications, data sourcing is a fundamental step. As Khalil and Ebner (2015) suggested, a life cycle of learning analytics includes a) data generation, b) data tracking, c) data analysis, and d) action (e.g., prediction, intervention and personalization). Without data, LA can hardly do anything.

However, to the best of our knowledge, current course learning design practices have not considered what and how data should be generated for learning analytics to use. Course learning design is an approach of crafting learning experiences in a learning environment where learners can achieve the expected learning outcomes. The lack of LA consideration in current course design practices can bring some challenges to LA implementation due to the requirements of data collection and pedagogical connection (Greller et al. 2014; Gašević et al. 2017; Tateo 2019).

\section{Data Collection Impact}

As students learn in increasingly open and complex learning environments, learning data are generated in unpredicted or unstructured formats and scattered in various platforms and devices (Chatti et al. 2012; Shankar et al. 2018). According to Chatti et al. (2012), the challenge is "how to aggregate and integrate raw data from multiple, heterogeneous sources, often available in different formats, to create a useful educational data set that reflects the distributed activities of the learner; thus leading to more precise and solid LA results" (p.8). Furthermore, learning can happen without leaving any digital traces, such as when students read textbooks offline. As Wilson et al. (2017) discovered, one limitation of the current course design practices is that "... in many cases, we do not observe learning online; we do not even observe students online" (p. 9).

Also, collecting a large volume of data from students' daily life could be regarded as an invasion of privacy (Chatti et al. 2014). There are serious and frequent concerns over privacy protection, data security, and ethical issues about the use of students' data (Wang 2016).

\section{Pedagogical Connection Impact}

Another limitation of the current course design practices is the lack of connections between learning analytics and learning theories (Mangaroska and Giannakos 2018; Tateo 2019). Such connections can provide in-depth and practical insights (explanatory power) for teachers to act on (Tateo 2019). While LA should be seen as an educational 
approach guided by pedagogy (Jivet et al. 2017), its implementation tends to focus more on technical rather than pedagogical aspects (Leitner et al. 2017). This deficiency leads to the current issue of misalignment between the information generated by learning analytics and the needs, problems, and concerns that educators have. As cited by Shum and Luckin (2019), "what counts can't always be measured, and what's measurable doesn't always count."

The reason for this misalignment can also be found in the gap between data easily captured from system logs and data that is pedagogically valuable (El Alfy et al. 2019). Many LA systems tend to analyze those data that are easily captured but poor proxies for learning, such as clicking data, basic online quiz scores and course grades (Gašević et al. 2015; Tempelaar et al. 2015). For example, Jivet et al. (2017) found that the development of many LA dashboards is primarily driven by the need to leverage the learning data available, rather than a clear pedagogical intention to improve learning.

\section{Calling for Data Sourcing Solutions}

As learning analytics providing summative data is often insufficient to reflect a clear picture of students' knowledge mastering and learning process (Rogers et al. 2016), many LA systems do not function well at a deeper level to recommend detailed and instructive insights on how to improve students' learning (Chatti et al. 2014). To address this issue, more cost-effective ways of sourcing the informed learning progress data should be explored (Wong and Li 2020).

\section{Learning Design for Data Sourcing}

In online education, learning design is a process of designing students' learning experience through a set of pedagogically informed learning activities that make effective use of appropriate resources, technologies, and support (Frizell and Hübscher 2011; Mangaroska and Giannakos 2018). Learning data, which LA is operating on, are mainly generated from students' interacting with the learning environments through learning activities (Shum and Crick 2012). As Tempelaar et al. (2013) suggested, "the prime data source for most learning analytic applications is the data generated by learner activities, such as learner participation in continuous formative assessments." (p.1). Therefore, how learning activities are designed in a course can determine whether or what learning data are generated. Since learning activities are planned in the course learning design process, this study suggests LA should be included in the loop of learning design so that the limitation on data collection and pedagogical connection can be addressed.

To date, most studies have focused on how learning analytics supports learning design by informing the creation of learning activities based on LA analysis results (Mangaroska and Giannakos 2018). Few studies have reported on how learning design practices facilitate the implementation of learning analytics. In practice, LA systems usually work on whatever data is available in a course.

To fill this gap, it is crucial to investigate a systematic way of including LA in the loop of course learning design. As Lockyer et al. (2013) pointed out, "learning designs provide a model for intentions in a particular learning context that can be used as a framework for the design of analytics to support faculty in their learning and teaching 
decisions" (p.4). Thus, this study will explore a new course learning design practice or a model that can facilitate LA implementation.

\section{The Proposed Model for Course Learning Design}

Since learning activities generate learning data, this study suggests sufficient and meaningful data-collection points are embedded in a course by designing certain learning activities. Students in SPOL have the freedom regarding how and where they learn as long as they complete the assignments and the examinations before finishing the course. If students do not log in to the learning system regularly and choose to learn offline most of the time, not much learning data will be recorded. However, if a course embeds a series of check-point activities (e.g., quizzes, posting, reflecting) in the system, regardless of how and where students learn, they will periodically come back to and interact with the learning system. This way, their learning progress, study pace, and knowledge and skill state can be consistently scanned and recorded in the learning system. Thus, by purposefully designing check-points activities, course instructors can pre-determine what, when, where and how learning data are generated and recorded during a student's learning journey. As suggested by Tateo (2019), "to address the needs of various stakeholders, we need to plan (e.g., when designing a course) before undertaking specific learning analytics activities."

Yet, such check-point activities cannot be placed in a course randomly and arbitrarily without considering their pedagogical effects. Rather, it is necessary to follow certain guidelines when designing such activities so that not only the necessary learning data can be generated but also the pedagogical needs can be met.

\section{Input Variables for LA Applications}

To design these check-point activities, the data sources or input variables should be determined first. Shum and Crick (2012) proposed a LA infrastructure, which stated that LA systems mainly operate on two types of data: learner data and learning data. Learner data include students' demographics, academic background, dispositions, learning preference, etc. Such data can be collected through surveys, self-report or student information systems. Learning data, however, are mainly generated from students' interacting with the learning environments through learning activities.

As different disciplines and learning contexts usually have different pedagogical needs, the learning data required by LA vary. This study has focused on the STEM (science, technology, engineering, and mathematics) disciplines in SPOL in higher formal education. Courses in STEM share some common pedagogical needs, such as STEM-related conceptual development, inquiry-based, problem-solving, real-world connection and using current tools and technologies (Kennedy and Odell 2014).

For STEM disciplines, this study recognizes that the following data sources are relevant to the LA applications suggested by this study for SPOL. Therefore, they should be considered during the course design stage.

- Academic background (SIS - Student Information System)

- Prior knowledge (Diagnostic test) 
- Learning interest (Survey or Log)

- Learning approach (Survey or Log)

- Knowledge state (Assessment)

- Attempts of formative assessment (Log)

- Time spent on the formative assessment (Log)

- Assessment Grade (Log)

- Access to learning materials recommended after the formative assessment (Log)

- Study schedule plan (LMS database)

- Study pace (Log)

- Social interactions $(\log )$

- Social style (Survey)

- Help-seeking frequency (Log)

Among these data sources, students' knowledge state (or knowledge and skill proficiency) is the most critical input variable for the LA applications. Most of the above data are relatively easy to be retrieved, either from system log, database, or survey. But estimating students' knowledge state is a challenging task. It is also a core task of student modelling in the field of artificial intelligence in education (AIED).

\section{Knowledge State Estimation}

Regarding the concept of student modelling for knowledge tracking, we are inspired by Jim Greer's work in AIED and his advocacy of using learning analytics for student modelling in online education. Jim Greer first focused his work on student modelling for intelligent tutoring systems (McCalla and Greer 1994). He, with Gordon McCalla, co-directed a NATO-sponsored workshop entitled "Student Modelling: The Key to Individualized Knowledge-Based Instruction", which was held May 4-8 of 1991 at Ste. Adele, Quebec, Canada. The results from this workshop are still significant today to the research in intelligent tutoring systems or adaptive learning systems. Later, Jim Greer advocated learning analytics as a student modelling approach in e-learning systems (Brooks and Greer 2014, March).

A few aspects are explored in student modelling, including learner profile, knowledge state, cognitive characteristics, social characteristics, motivation, affect, and personal traits (Abyaa et al. 2019; Pelánek 2017). One primary goal of student modelling is to estimate learners' current knowledge state and predict their future performance based on their past performance, such as in an assessment (Bodily et al. 2018; Pelánek 2017).

Modelling Knowledge State Research on student modelling is often grounded in artificial intelligence techniques and methods (Bodily et al. 2018). A variety of modelling approaches have been developed: clustering and classification (e.g., data mining), predictive modelling, overlay modelling (e.g., graph modelling, concept mapping), uncertainty modelling (e.g., Bayesian Networks), reinforcement learning (e.g., the multi-armed bandit algorithms), and ontology-based modelling.

Of these approaches, predictive modelling is used to estimate students' knowledge proficiency through computerized assessment, including auto-graded self-assessment. Predictive modelling uses algorithms like Item Response Theory (IRT) (Hambleton 
and Swaminathan 2013), Bayesian Knowledge Tracing (BKT) (Corbett and Anderson 1995), Deep Knowledge Tracing (DKT) (Piech et al. 2015), cognitive diagnosis models (De La Torre and Minchen 2014), and knowledge space theory (Falmagne et al. 1990). Among the algorithms, BKT has been widely researched and applied (Bassen et al. 2018).

Bayesian Knowledge Tracing (BKT) BKT was introduced in 1995 by Corbett \& Anderson to model students' knowledge as a latent variable in technologically enhanced learning environments (Corbett and Anderson 1995). In BKT, five probability parameters are identified for each student's skill, as shown in Fig. 1. Decades of research on student modelling resulted in a variety of improvements to the BKT approach (Yudelson et al. 2013).

Some recent research also explores DKT, an application of neural networks to predict academic performance. Although DKT has been reported to have more predicting accuracy in some cases, BKT is a more explanatory model (Pelánek 2017). Unlike DKT, the linkage of the BKT model to learning theory provides indepth and practical insights (explanatory power) for teachers to act on (Bodily et al. 2018; Bergner 2017).

Hence, when balancing between the explanatory power for insights and the predicting accuracy, BKT is a knowledge estimation option that acutely servers the purposes of learning awareness and academic intervention.

Embedding an Adaptive Mechanism in the Assessment To better estimate students' knowledge and skill proficiency, an adaptive mechanism using an appropriate knowledge estimation algorithm can be embedded in the assessment. Adaptive assessment or computer adaptive testing (CAT) is used to adapts to individual students' abilities by delivering a subsequent question based on their response to previous questions (Rezaie and Golshan 2015). Compared with the traditional fixed-form assessment, adaptive assessment can estimate a student's knowledge and skill proficiency in a more accurate, reliable, efficient, fast, and flexible way. Adaptive assessment also can promote learning motivation by avoiding too easy or too difficult questions (Rezaie and Golshan 2015).

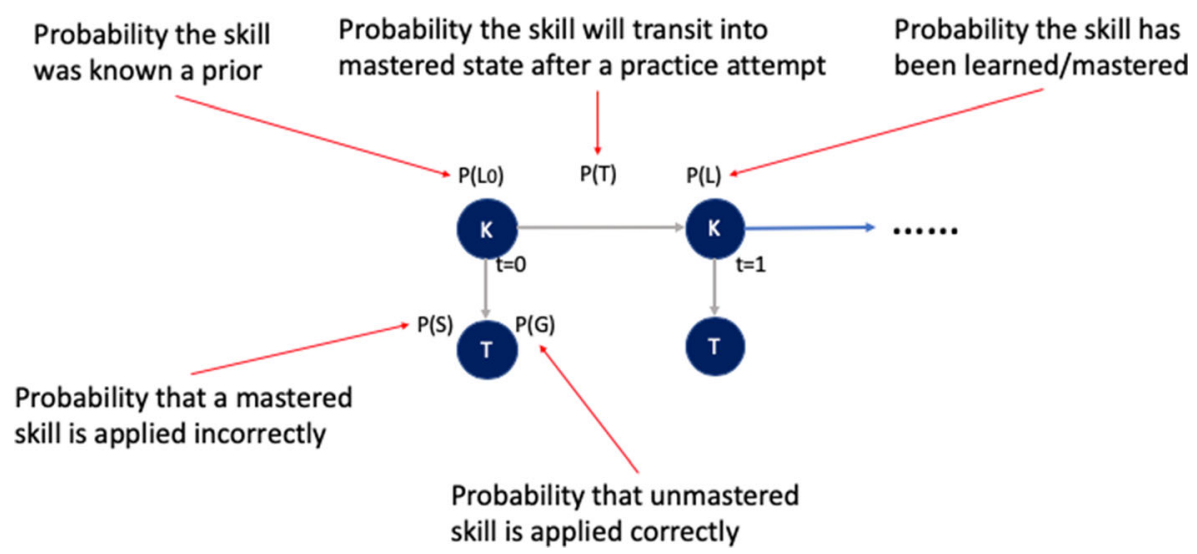

Fig. 1 Parameters of each skill of a student in BKT 
Many adaptive mechanisms have been developed in the literature. Some assume that a student's knowledge level does not change during a test (e.g., IRT or BKT), while some do consider knowledge change (e.g., multi-armed bandit) (Vie et al. 2017). Which adaptive mechanism should be adopted will depend on the purposes of the formative assessment. For example, a diagnostic test at the beginning of the course can be used to quickly estimate students' prior-knowledge. As such formative assessment is usually set with a time limit, students' knowledge will unlikely change during the test. So, an IRT approach would be appropriate. Formative assessment can also be created in a unit for promoting learning gain and identifying learning gaps. Usually, such formative assessment allows students to take time checking learning materials or synthesizing knowledge through studying the questions, hence students' knowledge or skill level could change during the test. In such cases, a reinforcement learning algorithm, such as the MAB, can be a better solution.

A MAB-based algorithm allocates a fixed and limited set of resources between competing (alternative) choices to maximize the expected gain when each choice's properties are only partially known at the time of allocation (Berry and Fristedt 1985; Gittins 1989). In the context of formative assessment, such a MAB-based algorithm can be used to dynamically allocate a certain number of questions to a variety of skills for students to practice. The goal can be to maximize a student's learning gain by optimizing the sequence of these questions when each skill level of the student is unknown or only partially known and possibly changing during the assessment process.

\section{The Proposed LDA Model}

Based on the relationship between learning design and learning analytics in SPOL, a model of learning design interacting with learning analytics is proposed in this study, called Learning Design-Analytic (LDA) model. The model is suggested mainly for STEM disciplines and illustrated in Fig. 2.

As illustrated in the model, course learning design that aims for learning success builds learning activities, which generate the learning data. These learning data can be used by learning analytics, which can potentially mitigate the learning barriers in SPOL, such as learning awareness, learning tracking, academic intervention and learning motivation. The improvement in these aspects can, in turn, promote learning success.

Learning activities (e.g., reading, exercising, assessment) are the means for students to achieve learning success. From the learning analytics' perspective, learning activities are the sources of learning data. One important type of learning activity is assessment, including formative assessment (such as self-conducted unit test). When formative assessment is adopted, students can use it to check their knowledge state (knowledge and skill proficiency) during the course. With the adaptive mechanism embedded in the formative assessment, the learning system can more efficiently and accurately estimate students' knowledge state at the topic level. Students' knowledge state is a core data source for the LA applications that aim to mitigate learning barriers in SPOL.

Another type of data source is the learner data, such as students' academic background, learning interest, learning approach, motivation, and social style. Such data can 


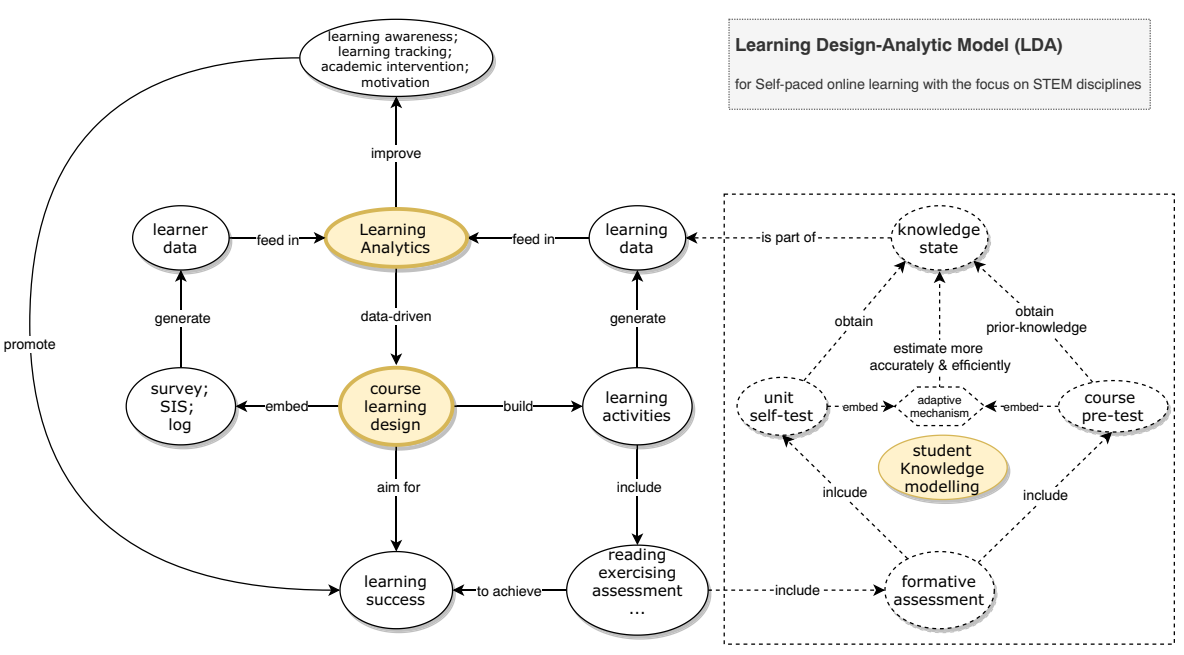

Fig. 2 The proposed LDA model for SPOL

be obtained from a survey on students, Student Information System, and the log of the learning system. The survey should be considered in the course learning design stage as well to determine the questions that can generate the genuine learner data required by the LA applications.

The analysis results from LA can, in turn, empower the course learning design by facilitating a data-driven approach. By analyzing students' learning data in the log and database, LA can detect which learning materials and activities need to improve or revise. Therefore, certain learning data should be generated, tracked, and analyzed. These data can be mapped out from the learning activities during the course design process.

On the right side of the LDA model flowchart (see Fig. 2 above), the nodes and arrows delineated with dotted lines indicate they are in the scope of student knowledge modelling. It shows that the core task of student modelling in this model is to employ an adaptive mechanism in the formative assessment to estimate students' knowledge state accurately and efficiently.

\section{Course Design Strategies for Including LA}

Based on the LA applications, the LDA model and the data sources determined for SPOL, the following course design strategies are recommended for including LA in the loop of learning design.

1) Add a diagnostic test and a learner profile survey

The diagnostic test at the beginning of a course can evaluate students' prior knowledge or entrance skills. A survey at the beginning of a course can collect students' academic profiles, such as academic background, learning interest, learning goals, learning approach, and social style.

2) Embed formative assessment throughout the course

Formative assessment refers to the assessment that can generate formative feedback on performance to accelerate learning (Sadler 1998). It is a systematic 
process to continuously gather evidence about learning (Heritage et al. 2009).

Embedding formative assessment in a course can allow students to reflect upon their learning, increase self-awareness, and identify their learning gap. Therefore, formative assessment should be an integral and vital part of learning systems to enhance learning (Hill and Barber 2014).

In STEM courses, as students predominately interact with learning content, automatic feedback from the learning system becomes essential. This study suggests auto-graded questions (e.g., multi-choice questions, fill-in-blank) should be used in the formative assessment. Auto-graded questions not only can provide timely feedback, but also can reduce human instructors' marking workload. Also, unlimited attempts and time should be enabled for the assessment.

Questions in the formative assessment should be used to test not only facts remembering and concepts understanding, but also STEM-related high-level skills mastering (e.g., sense-making, reasoning, problem-solving). Research has established that well-designed multiple-choice questions can assess such highlevel cognitive functions (Brady 2005; Leung et al. 2008; Draper 2009).

3) Record assessment data for LA to use

In formal higher education, virtual learning environments (VLE) are widely used for course delivery. While LA needs to retrieve data from the server-side of the VLE (e.g., logs or databases), students' interaction with VLE through the learning activities happens at the client-side. Thus, data generated from the client-side should be sent to the server-side for recording.

In order to encourage students to log into the learning system and conduct the formative assessment, some incentive strategies can be adopted. For example, a small portion of the course grade (for participation) can be allocated to the assessment; or, a certain engaging mechanism can be used, such as gamified learning.

4) Embed an adaptive mechanism in the assessment

As discussed in the previous section, adaptive assessment tailors to individual students' ability levels by asking questions in their zone of proximal development (ZPD) (Rezaie and Golshan 2015). An adaptive mechanism is encouraged to be used in the assessment to promote learning and identify learning gaps more effectively.

\section{Case Study}

To verify that the proposed course learning design strategies are practical and effective for LA implementation, we are conducting a case study with a computer science course - Computer Science 272 (COMP272): Data Structures and Algorithms - offered at Athabasca University of Canada. We selected this course because one of the authors of this paper is the course professor.

COMP272 is a challenging course in the program, with a relatively high academic failure rate (79\% pass rate compared to $89 \%$ the average program pass rate, in 2018). COMP272 consists of 13 learning units. It uses one open textbook as the primary reading resource, and a set of algorithm visualization (AV) exercises as the 
supplementary learning resource. Three assignments and one final examination are designed for summative assessment. Additionally, a Moodle discussion forum is created in each unit.

Like many online courses, the main design problem of the course is that little information can be tracked regarding how each student is learning through the course. Students rarely contact the course professor or the tutors, and only a small portion of students use the discussion forums. The AV exercises leave no learning records, and some students submit the assignments and take the examination at the very end of the course. Therefore, it is hard for the course professor or the tutors to track and monitor students' learning status, provide formative feedback, and offer proactive support to students who need extra help.

To solve the problem faced by COMP272, we have been investigating a variety of factors that need to be considered when revising the course by the professor. A design-based research (DBR) approach is used for this case study to explore whether the LDA model, the learning design strategies and the LA applications can help to increase the pass rates. Based on McKenney and Reeves' (2018) DBR model, this case study has been going through three stages: analysis \& exploration, design \& construction, and evaluation \& reflection. So far, the learning barriers identified in SPOL are confirmed by this course case, the course design strategies have been adopted for revision, and the LA applications proposed by this study have been put on the implementation list. Hence, the first analysis \& exploration stage has been completed.

\section{Course Redesigning}

At the current design stage, a series of learning activities have been planned by following the recommended course design strategies. These activities include a) a diagnostic test at the beginning of the course to check students' prior-knowledge, b) a survey placed at the beginning to obtain students' academic profiles, and c) formative assessment across the course (in each unit) to improve and estimate students' knowledge state.

The primary task at this design stage is to create a formative assessment for each unit. According to the design strategies for including LA in the loop, auto-graded self-quizzes are used to test facts, concepts, and high-level cognitive skills. The questions are in a multiple-choice or fill-in-the-blank format. Students can attempt the quizzes as many times as they want and as long as they need. To encourage students to log in to the learning system and take the quizzes, the following incentive strategies are employed: a) a small portion of the course grade is awarded for participating in the self-quizzes; b) a learning analytics dashboard (LAD) is being developed for the course; and c) a gamified learning tool, QuizMASter, is being developed for students. QuizMASter is a quiz game being developed by a team led by the course professor for students to self-check their knowledge proficiency and motivate themselves by competing with peers.

The following steps outline the question creation process.

\section{1) Knowledge graph}

To create the questions, the course professor has created a knowledge graph for each unit. Figure 3 is a sample of the knowledge graph of the unit Graph Algorithms. With 


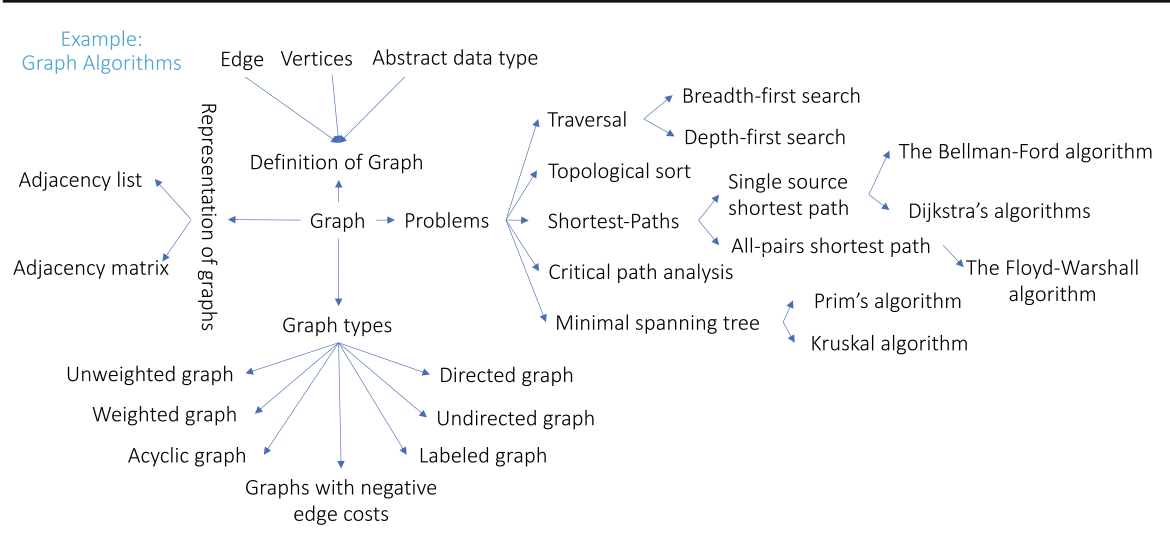

Fig. 3 Knowledge graph of the unit graph algorithm

the knowledge graph, a group of questions can be created for each knowledge component and each learning outcome. These learning outcomes are designed by referring to Bloom's taxonomy (Anderson et al. 2001).

\section{2) Questions}

So far, about 200 questions have been created to test facts and concepts. Some tags and indexes, such as the associated learning outcome, the difficulty level and the completion time, are attached to each question. The professor is also creating another 100 automarked exercises for high-level cognitive skills, borrowing the idea of JavaScript-based Algorithms Visualization (JSAV) (Karavirta and Shaffer 2013). Studies show that Algorithm Visualizations (AVs) are very effective in helping students master the algorithm concepts and skills (Shaffer et al. 2010). JSAV (http://jsav.io/) was developed for such AV activities by Karavirta and Shaffer (2013).

\section{3) Feedback}

For the learning gap detected through the formative assessment, further learning resources will be recommended to students. For example, for each question answered incorrectly by a student, the immediate feedback can indicate the learning materials that the student needs to work on. The Algorithm Visualization and Animations (AVA, https://algovis.athabascau.ca) is one such resource repository, developed by a group led by the course professor. Figure 4 is a sample of AVA animation.

\section{4) Adaptive mechanism}

An adaptive mechanism will be embedded in the formative assessment to accurately and efficiently estimate students' knowledge and skill proficiency. As pointed out in the design strategies section, for the diagnostic test at the beginning of the course to estimate students' background knowledge, an IRT approach can be considered. In contrast, for formative assessment created in each unit to promote learning gain and 


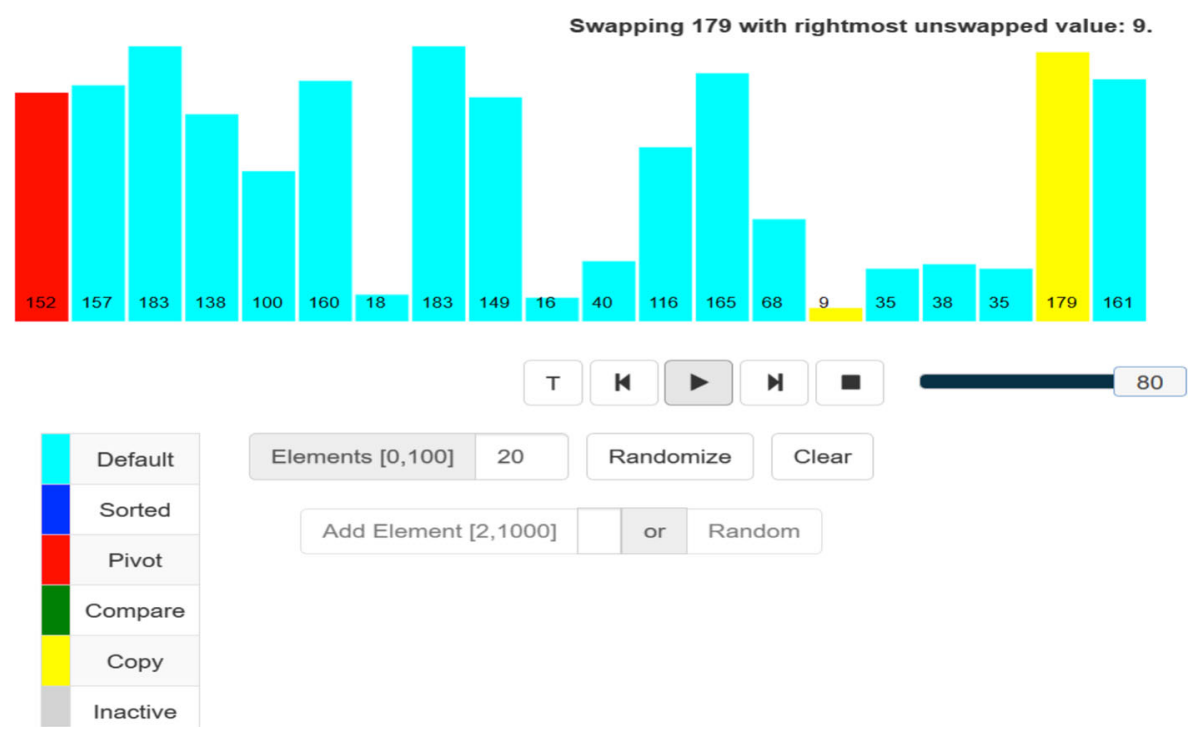

Fig.4 A sample AVA Animation

identify students' learning gaps, MAB algorithms are considered as the adaptive engine, such as Thompson Sampling based MAB algorithm (Lin 2020).

\section{System Construction Plan}

As of now, the design strategies are well adopted in this real course revision case. For the next stage of system construction, the following tasks are planned: a) implementing the adaptive mechanism in the formative assessment, b) developing an LA predictive application for identifying struggling students, c) building an LA dashboard for promoting learning awareness, and d) run the new version of the course to collect and analyze the data.

\section{System Evaluation Plan}

For the evaluation stage, we made a plan of evaluating the effectiveness of the system the adaptive mechanism in formative assessment and the LA applications - in addressing the learning barriers in SPOL. Multiple data sources will be collected from both the current course version and the new revised course version:

a) Log data in the learning system: For example, the grade, attempts of the assessment, time spent on the formative assessment, access of resources, and forum posts can tell if students' performance, engagement and social connections are increased.

b) Survey with students: Questions can be created to ask students if their self-awareness and self-regulation of learning, help-seeking behaviour and social connections are improved. This will help to evaluate the knowledge estimating the accuracy of the adaptive formative assessment and the LA predictive accuracy on the struggling students. 
After collecting the data, we will compare them between the current version and the new revised course version and find out if there is any significant difference because of the system we implemented. During the reflection stage, some improvement room of the system could be further identified from the design and implementation aspects.

\section{Conclusions and Future Work}

Removing the barriers in self-paced online learning calls for practical solutions. Given the enormous potential of LA, we presented an LDA model that aims to mitigate such learning barriers in STEM disciplines. We explained why and how LA should be integrated closely into the course learning design loop to ensure data collection and pedagogy connection for more meaningful LA implementation.

With the LDA model, we recommended a set of course design strategies for online educators who wish to use learning analytics in SPOL. One important strategy is to embed formative assessment throughout a course, such as unit self-quizzes for STEM disciplines. Inspired by Jim Greer's work on student modelling, we recommended using BKT as the student knowledge modelling approach and MAB as the adaptive mechanism for formative assessment. A case study using a work-in-progress course revision project has validated the practicality of the course design strategies. To further verify the effectiveness of the LDA model and the LA applications proposed in this study, plenty of work on system construction needs to be done in the next stage. Such work includes two key tasks from the research perspective in the context of SPOL: a) implementing the adaptive mechanism for formative assessment, and b) designing the predictive LA model for identifying struggling students. After the system construction for the new course version, the system evaluation and reflection will be conducted based on the data collected from the old and the new version of the course.

One limitation of the LDA model and the corresponding course design strategies is that they are mainly suitable for STEM disciplines. For example, the questions in the formative assessment need to be auto-graded for evaluating different cognitive skills, so that the computerized adaptive testing mechanism can be utilized. In other disciplines that need manual marking (such as for open-ended questions, text-based posts, or learning reflection), some new course design strategies or technologies (e.g., natural language processing) need to be explored. In addition, to better evaluate the effectiveness of the LDA model and the LA applications for removing learning barriers in SPOL, more online courses from STEM disciplines are expected to be used for case studies.

Funding Open access funding provided by University of Eastern Finland (UEF) including Kuopio University Hospital.

Open Access This article is licensed under a Creative Commons Attribution 4.0 International License, which permits use, sharing, adaptation, distribution and reproduction in any medium or format, as long as you give appropriate credit to the original author(s) and the source, provide a link to the Creative Commons licence, and indicate if changes were made. The images or other third party material in this article are included in the article's Creative Commons licence, unless indicated otherwise in a credit line to the material. If material is not included in the article's Creative Commons licence and your intended use is not permitted by statutory regulation or exceeds the permitted use, you will need to obtain permission directly from the copyright holder. To view a copy of this licence, visit http://creativecommons.org/licenses/by/4.0/. 


\section{References}

Abyaa, A., Idrissi, M. K., \& Bennani, S. (2019). Learner modelling: Systematic review of the literature from the last 5 years. Educational Technology Research and Development, 67(5), 1105-1143.

Anderson, L. W., Krathwohl, D. R., \& Bloom, B. S. (2001). A taxonomy for learning, teaching, and assessing: A revision of Bloom's taxonomy of educational objectives (Complete ed.). Longman.

Baker, R. S., \& Inventado, P. S. (2014). Educational data mining and learning analytics, In Learning Analytics (pp. 61-75). New York, NY: Springer.

Bassen, J., Howley, I., Fast, E., Mitchell, J., \& Thille, C. (2018, June). OARS: Exploring instructor analytics for online learning. In Proceedings of the Fifth Annual ACM Conference on Learning at Scale (pp. 1-10).

Bergner, Y. (2017). Measurement and its uses in learning analytics. In Handbook of Learning Analytics, (pp. 34 48). Society for Learning Analytics Research (SoLAR), 1 edition.

Berry, D. A., \& Fristedt, B. (1985). Bandit problems: Sequential allocation of experiments. (in book series: Monographs on statistics and applied probability). London: Chapman and Hall.

Bodily, R., Kay, J., Aleven, V., Jivet, I., Davis, D., Xhakaj, F., \& Verbert, K. (2018, March). Open learner models and learning analytics dashboards: A systematic review. In Proceedings of the 8th International Conference on Learning Analytics and Knowledge (pp. 41-50).

Brady, A. M. (2005). Assessment of learning with multiple-choice questions. Nurse Education in Practice, 5(4), 238-242.

Brooks, C., \& Greer, J. (2014, March). Explaining predictive models to learning specialists using personas. In Proceedings of the Fourth International Conference on Learning Analytics and Knowledge (pp. 26-30).

Carless, D., \& Boud, D. (2018). The development of student feedback literacy: Enabling uptake of feedback. Assessment \& Evaluation in Higher Education, 43(8), 1315-1325.

Chatti, M. A., Dyckhoff, A. L., Schroeder, U., \& Thüs, H. (2012). A reference model for learning analytics. International Journal of Technology Enhanced Learning, 4(5-6), 318-331.

Chatti, M. A., Lukarov, V., Thüs, H., Muslim, A., Yousef, A. M. F., Wahid, U., Greven, C., Chakrabarti, A., \& Schroeder, U. (2014). Learning analytics: Challenges and future research directions. eleed, Iss. 10.

Corbett, A. T., \& Anderson, J. R. (1995). Knowledge tracing: Modeling the acquisition of procedural knowledge. User Modeling and User-Adapted Interaction., 4(4), 253-278.

De La Torre, J., \& Minchen, N. (2014). Cognitively diagnostic assessments and the cognitive diagnosis model framework. Psicología Educativa, 20(2), 89-97.

Draper, S. W. (2009). Catalytic assessment: Understanding how MCQs and EVS can foster deep learning. British Journal of Educational Technology, 40(2), 285-293.

El Alfy, S., Marx Gómez, J., \& Dani, A. (2019). Exploring the benefits and challenges of learning analytics in higher education institutions: A systematic literature review. Information Discovery and Delivery, 47(1), 25-34.

Falmagne, J.-C., Koppen, M., Villano, M., Doignon, J.-P., \& Johannesen, L. (1990). Introduction to knowledge spaces: How to build, test, and search them. Psychological Review, 97(2), 201-224.

Frizell, S. S., \& Hübscher, R. (2011). Using design patterns to support E-learning design. In Management Association, I. (Ed.), Instructional design: Concepts, methodologies, tools and applications (pp. 114 134). IGI Global.

Gašević, D., Dawson, S., \& Siemens, G. (2015). Let's not forget: Learning analytics are about learning. TechTrends, 59(1), 64-71.

Gašević, D., Kovanović, V., \& Joksimović, S. (2017). Piecing the learning analytics puzzle: A consolidated model of a field of research and practice. Learning: Research and Practice, 3(1), 63-78.

Gittins, J. (1989). Multi-armed bandit allocation indices. Chichester New York: Wiley.

Greller, W., Ebner, M., \& Schön, M. (2014, June). Learning analytics: From theory to practice-data support for learning and teaching. In International Computer Assisted Assessment Conference (pp. 79-87). Springer, Cham.

Hambleton, R. K., \& Swaminathan, H. (2013). Item response theory: Principles and applications. Springer Science \& Business Media.

Heritage, M., Kim, J., Vendlinski, T., \& Herman, J. (2009). From evidence to action: A seamless process in formative assessment? Educational Measurement: Issues and Practice, 28(3), 24-31.

Hill, P., \& Barber, M. (2014). Preparing for a renaissance in assessment. London: Pearson Occasional Paper.

Jivet, I., Scheffel, M., Drachsler, H., \& Specht, M. (2017, September). Awareness is not enough: Pitfalls of learning analytics dashboards in the educational practice. In European Conference on Technology Enhanced Learning (pp. 82-96). Springer, Cham. 
Jovanović, J., Gašević, D., Dawson, S., Pardo, A., \& Mirriahi, N. (2017). Learning analytics to unveil learning strategies in a flipped classroom. The Internet and Higher Education, 33(4), 74-85.

Karavirta, V., \& Shaffer, C. A. (2013, July). JSAV: The JavaScript algorithm visualization library. In Proceedings of the 18th ACM conference on Innovation and technology in computer science education (pp. 159-164).

Kennedy, T. J., \& Odell, M. R. L. (2014). Engaging students in STEM education. Science Education International, 25(3), 246-258.

Khalil, M., \& Ebner, M. (2015, June). Learning analytics: Principles and constraints. In EdMedia+ Innovate Learning (pp. 1789-1799). Association for the Advancement of computing in education (AACE).

Lee, Y., \& Choi, J. (2011). A review of online course dropout research: Implications for practice and future research. Educational Technology Research and Development, 59(5), 593-618.

Leitner, P., Khalil, M., \& Ebner, M. (2017). Learning analytics in higher education-A literature review. In Learning analytics: Fundaments, applications, and trends (pp. 1-23). Springer, Cham.

Leung, S. F., Mok, E., \& Wong, D. (2008). The impact of assessment methods on the learning of nursing students. Nurse Education Today, 28(6), 711-719.

Lin, F. (2020). Adaptive quiz generation using Thompson sampling, Third Workshop Eliciting Adaptive Sequences for Learning (WASL 2020), co-located with AIED 2020.

Lockyer, L., Heathcote, E., \& Dawson, S. (2013). Informing pedagogical action: Aligning learning analytics with learning design. American Behavioral Scientist, 57(10), 1439-1459.

Mangaroska, K., \& Giannakos, M. (2018). Learning analytics for learning design: A systematic literature review of analytics-driven design to enhance learning. IEEE Transactions on Learning Technologies, 12(4), 516-534.

McCalla, G. I., \& Greer, J. E. (1994). Granularity-based reasoning and belief revision in student models. In Student modelling: The key to individualized knowledge-based instruction (pp. 39-62). Springer, Berlin, Heidelberg.

McKenney, S., \& Reeves, T. C. (2018). Conducting educational design research. Routledge.

Park, J. H., \& Choi, H. J. (2009). Factors influencing adult learners' decision to drop out or persist in online learning. Journal of Educational Technology \& Society, 12(4), 207-217.

Pelánek, R. (2017). Bayesian knowledge tracing, logistic models, and beyond: An overview of learner modeling techniques. User Modeling and User-Adapted Interaction, 27(3-5), 313-350.

Piech, C., Bassen, J., Huang, J., Ganguli, S., Sahami, M., Guibas, L. J., \& Sohl-Dickstein, J. (2015). Deep knowledge tracing. In Advances in Neural Information Processing Systems (pp. 505-513).

Rezaie, M., \& Golshan, M. (2015). Computer adaptive test (CAT): Advantages and limitations. International Journal of Educational Investigations, 2(5), 128-137.

Rogers, T., Gašević, D., \& Dawson, S. (2016). Learning analytics and the imperative for theory driven research. The SAGE Handbook of E-Learning Research, 232-250.

Sadler, D. R. (1998). Formative assessment: Revisiting the territory. Assessment in education: principles, policy \& practice, 5(1), 77-84.

Shaffer, C. A., Cooper, M. L., Alon, A. J. D., Akbar, M., Stewart, M., Ponce, S., \& Edwards, S. H. (2010). Algorithm visualization: The state of the field. ACM Transactions on Computing Education (TOCE), 10(3), 1-22.

Shankar, S. K., Prieto, L. P., Rodríguez-Triana, M. J., \& Ruiz-Calleja, A. (2018, July). A review of multimodal learning analytics architectures. In 2018 IEEE 18th International Conference on Advanced Learning Technologies (ICALT) (pp. 212-214). IEEE.

Shum, S. B., \& Crick, R. D. (2012, April). Learning dispositions and transferable competencies: Pedagogy, modelling and learning analytics. In Proceedings of the 2nd International Conference on Learning Analytics and Knowledge (pp. 92-101). ACM.

Shum, S. J. B., \& Luckin, R. (2019). Learning analytics and AI: Politics, pedagogy and practices. British Journal of Educational Technology, 50(6), 2785-2793.

Siemens, G., \& Long, P. (2011). Penetrating the fog: Analytics in learning and education. Educause Review, $46(5), 30-40$.

Stone, C. (2017). Opportunity through online learning: Improving student access, participation and success in higher education. Perth: The National Centre for student equity in higher education (NCSEHE), Curtin University.

Tateo, L. (2019). The journey of learning. Mind, Culture, and Activity, 26(4), 371-382.

Tempelaar, D. T., Heck, A., Cuypers, H., van der Kooij, H., \& van de Vrie, E. (2013, April). Formative assessment and learning analytics. In Proceedings of the Third International Conference on Learning Analytics and Knowledge (pp. 205-209). ACM. 
Tempelaar, D. T., Rienties, B., \& Giesbers, B. (2015). In search for the most informative data for feedback generation: Learning analytics in a data-rich context. Computers in Human Behavior, 47, 157-167.

Venant, R., Vidal, P., \& Broisin, J. (2016, July). Evaluation of learner performance during practical activities: An experimentation in computer education. In 2016 IEEE 16th International Conference on Advanced Learning Technologies (ICALT) (pp. 237-241). IEEE.

Vie, J. J., Popineau, F., Bruillard, É., \& Bourda, Y. (2017). A review of recent advances in adaptive assessment. In Learning Analytics: Fundaments, Applications, and Trends (pp. 113-142). Springer, Cham.

Wang, Y. (2016). Big opportunities and big concerns of big data in education. TechTrends, 60(4), 381-384.

Wilson, A., Watson, C., Thompson, T. L., Drew, V., \& Doyle, S. (2017). Learning analytics: Challenges and limitations. Teaching in Higher Education, 22(8), 991-1007.

Wong, B. T. M., \& Li, K. C. (2020). A review of learning analytics intervention in higher education (20112018). Journal of Computers in Education, 7(1), 7-28.

Yudelson, M. V., Koedinger, K. R., \& Gordon, G. J. (2013, July). Individualized bayesian knowledge tracing models. In International Conference on Artificial Intelligence in Education (pp. 171-180). Springer, Berlin, Heidelberg.

Zimmerman, B. J. (2000). Attaining self-regulation: A social cognitive perspective. In Handbook of Selfregulation (pp. 13-39). Academic press.

Publisher's Note Springer Nature remains neutral with regard to jurisdictional claims in published maps and institutional affiliations.

\section{Affiliations}

\section{Hongxin $\operatorname{Yan}^{1} \cdot$ Fuhua $\operatorname{Lin}^{2} \cdot$ Kinshuk $^{3}$}

1 School of Computing, University of Eastern Finland, Kuopio, Finland

2 School of Computing and Information Systems, Athabasca University, Athabasca, Canada

3 College of Information, University of North Texas, Denton, TX, USA 